\title{
Evaluation of the Effectiveness of Workplace Health Promotion Programs from 2000 to 2020: Literature Review
}

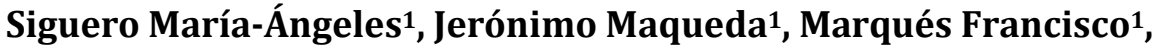 \\ Sagües María-Jesús ${ }^{1}$, Solé María-Dolores ${ }^{2}$
}

${ }^{1}$ Health Promotion and Occupational Epidemiology Department, National Institute for Safety and Health at Work, Madrid, Spain ${ }^{2}$ National Centre for Working Conditions, National Institute for Safety and Health at Work, Barcelona, Spain

Email: mariajesus.sagues@insst.mites.gob.es

How to cite this paper: María-Ángeles, S., Maqueda, J., Francisco, M., María-Jesús, S. and María-Dolores, S. (2021) Evaluation of the Effectiveness of Workplace Health Promotion Programs from 2000 to 2020: Literature Review. Open Journal of Preventive Medicine, 11, 113-131.

https://doi.org/10.4236/ojpm.2021.114010

Received: January 23, 2021

Accepted: April 5, 2021

Published: April 8, 2021

Copyright $\odot 2021$ by author(s) and Scientific Research Publishing Inc. This work is licensed under the Creative Commons Attribution International License (CC BY 4.0).

http://creativecommons.org/licenses/by/4.0/

\begin{abstract}
Introduction. Recognition of best practices in workplace health promotion is an important task that significantly affects the expansion of those programs. Once the program has been developed, its effectiveness becomes the most critical point of evaluation to guarantee achievements in the improvement of workers' health. Objectives. To identify the practices for evaluating the effectiveness of workplace health promotion programs. Material and Methods: A search was performed on MEDLINE through PubMed with the MeSH: "Occupational Health", "Health Promotion" and "Program Evaluation", from the year 2000 to the year 2020 for studies with the following designs: Meta-analyses, Systematic reviews, Randomized Clinical Trials and Clinical Trials. Results: The most common topic of workplace health promotion programs (WHP) was increasing physical activity and avoiding a sedentary lifestyle, followed by stress management and finally smoking cessation and musculoskeletal disorders. The post-intervention measurements were most often done at 6 months and 12. The most commonly used indicators were the number of steps, weight, BMI, \% body fat, waist circumference, blood pressure, sedentary time, level of physical activity and time of moderate-vigorous physical activity, daily energy output, life purpose, life satisfaction, mood and stress level. Conclusions: Although a great variability was observed in the evaluation of WHP programs, there were also common aspects. These results will help with designing WHP programs and defining evidence-based evaluation of their effectiveness. It is important to remember that WHP programs must be customized, taking into consideration the needs of each organization's workforce.
\end{abstract}




\section{Keywords}

Occupational Health, Health Promotion, Effectiveness Evaluation

\section{Introduction}

The European Network for Work Place Health Promotion (ENWHP) was formally established in 1996 [1], and since then it has overseen the course of Work Health Promotion (WHP) in Europe. Throughout its history, it has published various initiatives along with national institutes for workplace health and safety, public health institutes, social security institutes and the European Commission, among other collaborating entities. These initiatives seek to answer questions aimed at improving WHP [2]. The trajectory of its more global initiatives is shown in Figure 1.

The 4th initiative to support the national development of WHP through forums and a "toolbox" [3] served to strengthen the relationship between National Safety and Health at Work Institutes and the ENWHP, ENWHP initiatives are promoted in European countries and research about aspects related to the health of European workforce is driven.

In addition, the Department of Health Promotion and Occupational Epidemiology (DEPROSEL) works on the Spanish Network of Healthy Companies

1 st

2nd

3rd

4 th

5 th

•(2004-2006) Healthy Work in an Aging Europe

-(2005-2007) Disseminating Good Workplace Health in Eastern 6th European Countries

-(2007-2009) Move Europe - Healthy Lifestyles in the Working 7th Environment

8th

•(2009-2010) Work in Tune with Life - Mental Health

-(2011-2013) Promoting Healthy Work for People with Chronic Illness. 9th Public Health and Work

Figure 1. ENWHP initiatives. 
(REES). Each year, the DEPROSEL evaluates dozens of WHP programs from different companies; if the result obtained using the established evaluation process is favorable, the Spanish National Institute for Safety and Health at Work (INSST) grants the recognition of Best Practices (BP) in WHP Model Company to organizations concerned with the WHP of their workplaces.

In this sense, vast heterogeneity has been observed in the evaluation of companies' WHP programs. This may be an obstacle to the development of WHP.

Although the theory may seem simple, problems occur when measuring health changes that workers have "had to" experience as a result of the WHP interventions - that is, their effectiveness. Currently, the way to measure the effectiveness of WHP programs is planned from the time of design of the intervention; however, it still seems that there is no consensus about what to measure and how to measure it.

This problem of evaluating the results of WHP interventions leads to various questions, such as: whether the time spent is sufficient for changes to manifest, whether the content of the intervention was actually right or how to measure its effectiveness. This last aspect revolves around indicators, aspects that must be assessed to determine the changes obtained after any intervention. It is just as important to know the techniques that will be used to measure those indicators as it is to know which indicators will be selected.

The ENWHP recommends several tools for evaluating the quality of WHP programs, such as the ENWHP Quality Criteria or the Mental Health Check [4] [5]. In addition, along with these two questionnaires, provides resources: Move Europe Questionnaire: Tobacco, Physical Activity, Nutrition and Stress, Age Management Questionnaire, Chronic Diseases Management Questionnaire and the questionnaire on Health and Mental Wellbeing for SMEs [5].

In this sense, the lack of consensus about how to measure the effectiveness of WHP programs justifies the creation of the concept of Best Practices as an operative term in WHP. Kahan and Goodstadt define it as "set of processes and activities that is consistent with health promotion values, theories, evidence and understanding of the environment and that are most likely to achieve health promotion goals in any given situation." [6].

Additionally, the most common and effective WHP interventions at organizations focus mainly on increasing physical activity and avoiding a sedentary lifestyle, having proper nutrition, quitting smoking or reducing tobacco consumption, preventing alcohol consumption and other addictions, weight management and obesity, mental health and stress management, work-life balance, and active aging [7].

Based on the wide variety in evaluating the effectiveness of WHP programs, the matter is what are the existing practices for evaluating WHP interventions at an international level since 2000. Even if there is no formal consensus, are there similarities in how the effectiveness of WHP programs has been evaluated between 2000 and 2020 ? 


\section{Objectives}

The primary objective is to know the most commonly used practices for evaluating the effectiveness of workplace health promotion (WHP) programs from 2000-2020.

The specific objectives are: 1) to define the indicators most commonly used in evaluating WHP programs; 2) to catalog the topics most frequently addressed in WHP programs; and 3) to determine the frequency with which WHP programs are evaluated.

\section{Materials and Methods}

A bibliographic search was carried out in the MEDLINE database through PubMed public access. Controlled language was used with the MeSH "Occupational Health" "Health Promotion" and "Program Evaluation" and the Boolean operator "AND". The search strategy was as follows: ("Occupational Health" [Mesh] AND "Health Promotion" [Mesh] AND "Program Evaluation" [Mesh]).

Furthermore, the search was limited in time, by the design of the studies and to a human population. Therefore, the following filters were activated on PubMed: Meta-Analysis, Systematic Reviews, Clinical trial, Controlled Clinical Trial, Multicenter study, Randomized Controlled Trial, from 2000/01/01 to 2020/01/01, species: humans.

Although WHP has not yet reached all workplaces or all workers worldwide, much work is currently being done in this regard. Therefore, the decision was made to limit the review to since the year 2000, when WHP programs began to be more popular. This way, the focus was on how work has been carried out in this field, to continue studying the effectiveness of WHP programs in a more homogeneous way.

The types of studies selected met the need to collect indicators used to evaluate the effectiveness of WHP programs. Therefore, the review focused on studies of greater evidence, without disregarding systematic reviews and meta-analyses.

The age filter was not activated because the minimum legal working age in each country can vary; for example, there are 16-year-old workers.

Table 1 presents the inclusion and the exclusion criteria applied to form the collection of studies for analysis.

The inclusion criteria reflect the intent of the review and means that studies not sharing the same objective will not be analyzed. As for the exclusion criteria and in particular the second one, it is true that the process evaluation on the implementation of a WHP program at the organization is relevant. However, for that analysis, many varied factors must be considered. For example, the environment and socioeconomic profile of the company: sector of activity, cultural level; the relevance of the positions along with the authority of program leaders or changes in work organization motivated by crises in the country. Nevertheless, it is interesting to analyze how these organizational aspects influence WHP 
Table 1. Eligibility criteria.

\begin{tabular}{|c|c|}
\hline Inclusion criteria & $\begin{array}{l}\text { - Studies that provide quantitative and/or qualitative evidence on eval- } \\
\text { uation of the effectiveness of WHP programs. }\end{array}$ \\
\hline Exclusion criteria & $\begin{array}{l}\text { - Studies that do not provide result indicators to measure the effective- } \\
\text { ness of the WHP program; } \\
\text { - Studies focused on process evaluation of the implementation of WHP } \\
\text { programs; } \\
\text { - Studies that expose interventions limited to health surveillance; } \\
\text { - Studies that address the prevention of occupational diseases, limited } \\
\text { to occupational risk prevention measures. }\end{array}$ \\
\hline
\end{tabular}

programs. In fact, they could be the subject of future research.

A summary table was used for systematic reading of the articles included in the study collection and organization of their information.

\section{Results}

With the search equation stated, 36 publications were obtained on PubMed.

After reading all their abstracts, the decision was made not to include 5 of them because they did not meet the established inclusion criteria. Furthermore, despite appearing in the PubMed results, one of the studies was not available, so it was excluded from the collection.

Applying the exclusion criteria, 7 studies were eliminated for not providing result indicators to measure the effectiveness of the WHP program. In fact, 2 of those studies had not even been carried out. Furthermore, 6 studies were excluded for focusing on process evaluation of the implementation of WHP programs. The screening process for the study collection is shown in Figure 2.

In total, 19 studies of the 36 initially obtained were eliminated. Thus, the final study collection is formed by 17 articles.

The collection is briefly described on (Table 2). Table 3 synthesizes the information provided with special attention to the evaluation profile of interest for the review: actions, topics and indicators.

Reutman [8] conducted, in 2019, a quasi-experimental study to evaluate the effectiveness of a WHP intervention on physical activity that involved donating money raised based on the number of steps taken by 8 workers from a company in the United States (US) over the course of 2 weeks. They had to walk a minimum of 3000 steps a day and $\$ 20$ would be donated. They measured the number of steps per day and the US dollars raised at the end of the intervention. There has possible screening bias because of very small sample size.

A randomized clinical trial (RCT) was conducted, in 2019, by Das [9] to evaluate the effectiveness of a WHP program to improve wellbeing in 220 workers from 12 organizations in the US. For this, the trial measured the indicators vitality with the SF-36 Medical Outcome Survey (MOS) (8 subscales), purpose in life with the Ryff Purpose in Life Scale, physical activity with the International Physical Activity Questionnaire (IPAQ) and quality of life (QoL) by measuring 


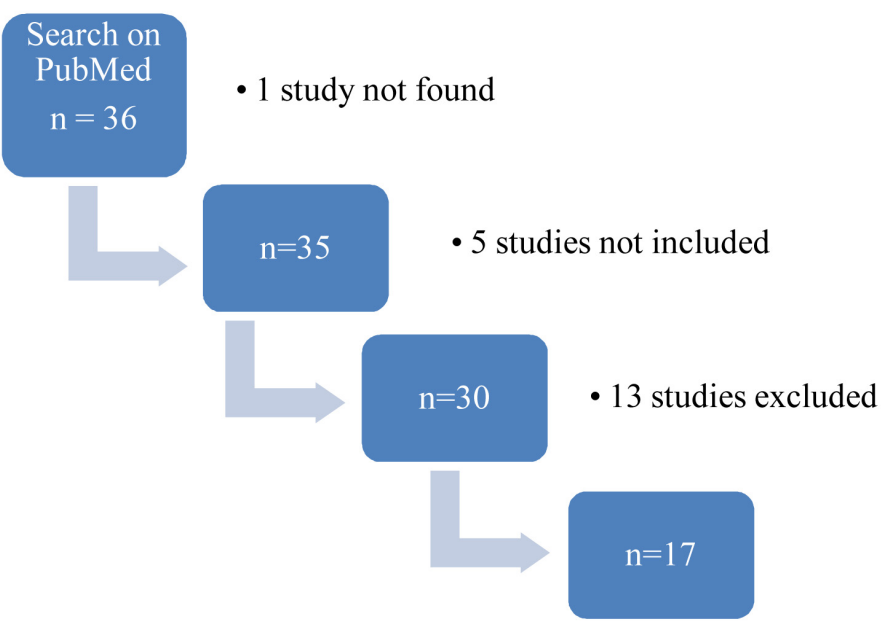

Figure 2. Flowchart of the article selection process.

sleep with the Optimal Sleep Scale, mood with the Profile of Mood States (POMS) and depression with the Center for Epidemiologic Studies Depression (CESD); in addition, it collected the following anthropometric measurements: weight, body mass index (BMI), \% body fat, total, HDL and LDL cholesterol, glycated hemoglobin and blood pressure (BP). Measurements were taken at the start and after 6 months.

Sandercock [10], in 2018, conducted a systematic review to evaluate WHP programs on physical activity and nutrition and their impact on workers' body composition. It analyzed 23 studies: 21 articles measured BMI $\left(\mathrm{kg} / \mathrm{m}^{2}\right), 7$ measured weight (kg), 6 measured \% body fat and 3 measured waist circumference $(\mathrm{cm})$, a predictor of cardiovascular $(\mathrm{CV})$ risk. In addition, 9 articles measured several of these four parameters together. With respect to the frequency of evaluation, all the articles took initial measurements and 9 articles measured at 12 months, 3 articles at 18 months, 6 articles at 24 months, 1 article at 36 months, 3 articles at 48 months and 1 article at 96 months. However, they did not specify whether extra measurements were performed in addition to the end-of-intervention measurement.

In 2018, Maylor [11] conducted an ECT to measure the effectiveness of a WHP intervention on sedentary lifestyle and physical activity to reduce the time spent seated by 89 office workers in the United Kingdom. To do that, the trial measured the time the workers were seated (in minutes) at work (differentiating whether these times were greater or less than thirty minutes), the number of times they got up during the day, the time spent walking and the number of steps; for CV health, the trial measured waist circumference, \% body fat, BP, total cholesterol and HDL cholesterol at the start and after 2 months.

Van Hoye [12], in 2018, conducted an RCT to evaluate maintenance of changes that can be achieved by a physical activity (PA), according to type of feedback for motivation of 227 workers in Belgium. They were given a pedometer, informed about their energy output and a trainer was made available to them. 
Table 2. Description of work health promotion articles reviewed.

\begin{tabular}{|c|c|c|c|c|c|c|}
\hline \multirow[b]{2}{*}{ Ref } & \multicolumn{6}{|c|}{ Main information recovered } \\
\hline & Title & Year & Author & Study design & $\begin{array}{l}\text { Sample size } \\
\text { (workers) }\end{array}$ & Conclusions \\
\hline$[8]$ & $\begin{array}{l}\text { A Workplace Demonstration } \\
\text { of a Proposed Alternative } \\
\text { Strategy to Incentivize } \\
\text { Workers to Engage in Physical } \\
\text { Activity. Workplace Health. }\end{array}$ & 2019 & Reutman S & Quasi-experimental & 8 & $\begin{array}{l}\text { The program participants were } \\
\text { successful at promoting physical activity } \\
\text { of workers for } 2 \text { weeks. Future worksite } \\
\text { health promotion projects with this type } \\
\text { of incentive strategy are indicated. }\end{array}$ \\
\hline [9] & $\begin{array}{l}\text { Effectiveness of an Energy } \\
\text { Management Training Course } \\
\text { on Employee Well-Being: A } \\
\text { Randomized Controlled Trial. }\end{array}$ & 2019 & Das SK & RCT & 220 & $\begin{array}{l}\text { An intensive } 2.5 \text {-day intervention } \\
\text { showed improvement in employee } \\
\text { Quality of live and well-being } \\
\text { over } 6 \text { months. }\end{array}$ \\
\hline [10] & $\begin{array}{l}\text { Evaluation of Worksite } \\
\text { Wellness Nutrition and } \\
\text { Physical Activity Programs } \\
\text { and Their Subsequent Impact } \\
\text { on Participants' Body } \\
\text { Composition. }\end{array}$ & 2018 & Sandercock V & Systematic review & 23 studies & $\begin{array}{l}\text { Evidence supports that worksite } \\
\text { wellness programs that are designed } \\
\text { using a motivational theory and } \\
\text { content based on participants' needs } \\
\text { and that has frequent interactions } \\
\text { with participants may result in a } \\
\text { change in body composition. }\end{array}$ \\
\hline [11] & $\begin{array}{l}\text { Efficacy of a Multicomponent } \\
\text { Intervention to Reduce } \\
\text { Workplace Sitting Time in } \\
\text { Office Workers: A Cluster } \\
\text { Randomized Controlled Trial. }\end{array}$ & 2018 & Maylor BD & RCT & 89 & $\begin{array}{l}\text { Multicomponent workplace } \\
\text { intervention was successful in } \\
\text { reducing prolonged sitting and } \\
\text { increasing physical activity in the } \\
\text { workplace. }\end{array}$ \\
\hline [12] & $\begin{array}{l}\text { Year-round effects of a } \\
\text { four-week randomized } \\
\text { controlled trial using different } \\
\text { types of feedback on } \\
\text { employees' physical activity. }\end{array}$ & 2018 & Van Hoye K & RCT & 227 & $\begin{array}{l}\text { It is recommended the feedback with a } \\
\text { personal coaching in order to facilitate } \\
\text { long-term behavioral change. When it } \\
\text { comes to increasing minutes of daily } \\
\text { moderate-to-vigorous physical activity } \\
\text { or total energy expenditure, a } \\
\text { pedometer constitutes a sufficient tool. }\end{array}$ \\
\hline [13] & $\begin{array}{l}\text { Feasibility and Effect of a } \\
\text { Peer Modeling Workplace } \\
\text { Physical Activity } \\
\text { Intervention for Women. }\end{array}$ & 2018 & Rowland SA & RCT & 52 & $\begin{array}{l}\text { Although physical activity increased } \\
\text { health parameters in both groups, } \\
\text { The Intervention Group showed a } \\
\text { greater improvement in fitness } \\
\text { and cardiovascular risk. }\end{array}$ \\
\hline [14] & $\begin{array}{l}\text { Promoting physical activity } \\
\text { in worksite settings: results } \\
\text { of a German pilot study } \\
\text { of the online intervention } \\
\text { Healingo fit. }\end{array}$ & 2017 & Dadaczynski K & $\mathrm{RCT}$ & 144 & $\begin{array}{l}\text { Pedometer-based interventions using } \\
\text { gamification can have positive effects } \\
\text { on health promotion and can also lead } \\
\text { to an increase in physical activity } \\
\text { behavior. The online format of } \\
\text { Healingo Fit is suitable for } \\
\text { achieving population effects. }\end{array}$ \\
\hline$[15]$ & $\begin{array}{l}\text { Moving to business - changes } \\
\text { in physical activity and } \\
\text { sedentary behavior after } \\
\text { multilevel intervention in small } \\
\text { and medium-size workplaces. }\end{array}$ & 2017 & Aittasalo M & Quasi-experimental & 296 & $\begin{array}{l}\text { Employees' physical activity increased } \\
\text { and sedentary behavior reduced at } \\
\text { work during the intervention. }\end{array}$ \\
\hline [16] & $\begin{array}{l}\text { Insights for Exercise } \\
\text { Adherence From a Minimal } \\
\text { Planning Intervention to } \\
\text { Increase Physical Activity. }\end{array}$ & 2015 & Chapman J & $\mathrm{RCT}$ & 254 & $\begin{array}{l}\text { A minimal, online planning } \\
\text { intervention on physical activity may } \\
\text { be useful for preventing long-term } \\
\text { relapse and assisting people to } \\
\text { improve regular exercise routines. }\end{array}$ \\
\hline
\end{tabular}


Reducing Metabolic Syndrome

[17] Risk Using a Personalized Wellness Program.

The effects of a physical activity intervention on

[18] employees in small and medium enterprises: a mixed methods study.

Promoting walking among office employees-evaluation

[19] of a randomized controlled intervention with pedometers and e-mail messages.

Worksite stress management

[20] training: moderated effects and clinical significance.

A randomized, controlled

[21] trial of financial incentives for smoking cessation.

Effectiveness of an at-work exercise program in the prevention and management of neck and low back complaints in nursery school teachers.

Effects of a worker participatory program for improving work environments on job stressors and mental health among workers: a controlled trial.

A brief mindfulness-based

[24] stress reduction intervention for nurses and nurse aides.
Steinberg G

RCT

1395

Edmunds S

Quasi-experimental

89

201

Aittasalo M

RCT

241

Flaxman PE

RCT
2006

Mackenzie CS
A personalized wellness program on reducing employees' future risk of metabolic syndrome would, lead to a significant improvement of clinical outcomes relative to three of five metabolic factors and a reduction in costs.

It is effective to train employees in small and medium sized enterprises to support their colleagues in physical activity behavior change.

To promote office-employees' walking by means pedometers and e-mail messages showed only modest impact on some indicators of walking.

A stress management training (SMT) programs improved to a clinically significant degree. The study highlights the importance of accounting for sample heterogeneity when evaluating and classifying worksite SMT programs.

Financial incentives for smoking cessation significantly increased the rates of smoking cessation.

A significant improvement was registered in the experimental group. An oriented exercise program may be a useful strategy to prevent low back and neck complaints and to reduce functional disability among nursery school teachers.

An organizational intervention using a participatory approach to improve work environments for worker mental health Showed an improvements in the outcomes among departments with a $50 \%$ or higher rate of worker participation in the planning workshops and among departments with a $50 \%$ or higher rate of implemented vs. planned actions.

Participants in the mindfulness intervention experienced significant improvements in burnout symptoms, relaxation, and life satisfaction. Mindfulness training is a promising method for helping those in the nursing profession to manage stress. 
Table 3. Evaluation profile.

\begin{tabular}{|c|c|c|c|c|}
\hline \multirow[b]{2}{*}{ Ref. } & \multicolumn{4}{|c|}{ Evaluation profile } \\
\hline & Action & $\begin{array}{l}\text { Work Health } \\
\text { Promotion Topic }\end{array}$ & Indicators & Measuring frequency \\
\hline$[8]$ & $\begin{array}{l}\text { Donate money raised according to } \\
\text { number of steps }\end{array}$ & $\begin{array}{l}\text { Physical Activity and } \\
\text { Sedentary Lifestyle }\end{array}$ & Number of steps per day & $\begin{array}{l}\text { Donate money raised according } \\
\text { to number of steps }\end{array}$ \\
\hline$[9]$ & US dollars raised & $\begin{array}{l}\text { Post-intervention: after } \\
2 \text { weeks }\end{array}$ & $\begin{array}{l}\text { Vitality (SF-36 Medical } \\
\text { Outcome Survey [MOS]) }\end{array}$ & US dollars raised \\
\hline$[10]$ & Analyzes 23 studies & $\begin{array}{l}\text { Physical Activity and } \\
\text { Sedentary Lifestyle. }\end{array}$ & $\begin{array}{l}\text { Purpose in life (Ryff } \\
\text { Purpose in Life Scale) }\end{array}$ & $\begin{array}{l}\text { Pre-intervention and after } 12 \\
\text { months, } 18 \text { months, } 24 \text { months, } \\
36 \text { months, } 48 \text { months, } 96 \\
\text { months }\end{array}$ \\
\hline$[11]$ & Reduce sedentary time at the office & Nutrition. & $\begin{array}{l}\text { Physical activity (International } \\
\text { Physical Activity } \\
\text { Questionnaire [IPAQ]) }\end{array}$ & $\begin{array}{l}\text { Pre-intervention and } 2 \\
\text { months post }\end{array}$ \\
\hline$[12]$ & $\begin{array}{l}\text { Consider most motivating feedback } \\
\text { for maintaining habit changes }\end{array}$ & $\begin{array}{l}\text { Physical Activity and } \\
\text { Sedentary Lifestyle }\end{array}$ & Sleep (Optimal Sleep Scale) & $\begin{array}{l}\text { Pre-intervention and } 1 \text { week, } \\
3 \text { months, } 6 \text { months and } 12 \\
\text { months post }\end{array}$ \\
\hline$[13]$ & $\begin{array}{l}\text { Health Education (HE) sessions, } \\
\text { and experiences that the most } \\
\text { active workers shared with those } \\
\text { who were less active }\end{array}$ & $\begin{array}{l}\text { Physical Activity and } \\
\text { Sedentary Lifestyle }\end{array}$ & $\begin{array}{l}\text { Mood state (Profile of Mood } \\
\text { States [POMS]) }\end{array}$ & $\begin{array}{l}\text { Pre-intervention and } 12 \\
\text { months post }\end{array}$ \\
\hline$[14]$ & $\begin{array}{l}\text { Measure knowledge acquired in } \\
\text { online sessions using a proprietary } \\
\text { four-item system }\end{array}$ & $\begin{array}{l}\text { Physical Activity and } \\
\text { Sedentary Lifestyle }\end{array}$ & $\begin{array}{l}\text { Depression (Center for } \\
\text { Epidemiological } \\
\text { Studies-Depression [CESD]) }\end{array}$ & $\begin{array}{l}\text { Pre-intervention and } 1 \text { and a } \\
\text { half months post }\end{array}$ \\
\hline$[15]$ & Evaluate changes in health habits & $\begin{array}{l}\text { Physical Activity and } \\
\text { Sedentary Lifestyle }\end{array}$ & Weight & $\begin{array}{l}\text { Pre-intervention and } 12 \\
\text { months post }\end{array}$ \\
\hline$[16]$ & Evaluate changes in health habits & $\begin{array}{l}\text { Physical Activity and } \\
\text { Sedentary Lifestyle }\end{array}$ & BMI & $\begin{array}{l}\text { Pre-intervention and } 6 \\
\text { months post }\end{array}$ \\
\hline$[17]$ & Evaluate changes in health habits & $\begin{array}{l}\text { Physical Activity and } \\
\text { Sedentary Lifestyle }\end{array}$ & $\%$ body fat & $\begin{array}{l}\text { Pre-intervention and } 12 \\
\text { months post }\end{array}$ \\
\hline$[18]$ & Evaluate changes in health habits & $\begin{array}{l}\text { Physical Activity and } \\
\text { Sedentary Lifestyle. }\end{array}$ & Cholesterol (total, HDL, LDL) & $\begin{array}{l}\text { Pre-intervention and } 6 \\
\text { months post }\end{array}$ \\
\hline [19] & $\begin{array}{l}\text { Promote walking among office } \\
\text { workers }\end{array}$ & Nutrition & Glycated hemoglobin & $\begin{array}{l}\text { Pre-intervention and } 2 \text { months, } \\
6 \text { months and } 12 \text { months post }\end{array}$ \\
\hline$[20]$ & Evaluate changes in health habits & $\begin{array}{l}\text { Physical Activity and } \\
\text { Sedentary Lifestyle }\end{array}$ & Blood pressure & $\begin{array}{l}\text { Pre-intervention and } 3 \text { months, } \\
6 \text { months and post }\end{array}$ \\
\hline$[21]$ & $\begin{array}{l}\text { Give employees monetary } \\
\text { incentives to quit smoking }\end{array}$ & $\begin{array}{l}\text { Physical Activity and } \\
\text { Sedentary Lifestyle }\end{array}$ & BMI & $\begin{array}{l}\text { Pre-intervention and } 6 \text { months, } \\
12 \text { months and } 18 \text { months post }\end{array}$ \\
\hline$[22]$ & $\begin{array}{l}\text { Prevent and manage cervical and } \\
\text { low back pain }\end{array}$ & Stress and Mindfulness & Weight & $\begin{array}{l}\text { Pre-intervention and } 2 \\
\text { months post }\end{array}$ \\
\hline [23] & Evaluate changes in health habits & Smoking cessation & $\%$ body fat & $\begin{array}{l}\text { Pre-intervention and } 12 \\
\text { months post }\end{array}$ \\
\hline$[24]$ & Evaluate changes in health habits & Ergonomics and MSDs & Waist circumference & $\begin{array}{l}\text { Pre-intervention and } 1 \\
\text { month post }\end{array}$ \\
\hline
\end{tabular}


For this trial, the following was measured: daily PA level, calculated according to metabolic equivalent of tasks (METs) and also using the Flemish Physical Activity Computerized Questionnaire (FPACQ); the number of steps per day, the minutes of moderate-vigorous PA per day and the energy output per day at the start, after 1 week, at 3 months, 6 months and 12 months.

An RCT was conducted, in 2018, by Rowland [13] to evaluate the effectiveness of a WHP intervention on nutrition and physical activity in 52 female workers in the US. In addition to health education (HE) sessions, it focused on evaluating the usefulness of sessions in which the most physically active workers, in pairs, shared their experience with those who were less active. It measured maximum oxygen consumption to see physical aptitude, moderate or intense PA levels, weekly time and blood glucose, cholesterol, LDL, HDL and triglyceride (TG) levels, BMI and CV risk with the Lifetime Cardiovascular Risk Calculator at the start and after 12 months.

Dadaczynski [14], in 2017, conducted an RCT to evaluate a WHP intervention on physical activity in 144 workers in Germany. It measured the knowledge acquired in online sessions with a proprietary four-item system, the intent and self-sufficiency of workers in relation to PA, also with proprietary items, and measured weekly PA with the 7-item IPAQ-SF at the start and after 1 and a half months.

A quasi-experimental study was conducted in 2017 by Aittasalo [15] to evaluate changes in health habits after a WHP intervention on sedentary lifestyle and physical activity at 12 small and medium enterprises (SMEs) with 296 workers in Finland. It used the National Questionnaire of Finland, with questions about PA, sedentary lifestyle, tobacco use, perceived state of health, sleep and rest. It also measured time of PA performed at work and outside of it, number of steps at work and outside of it, time seated at work and outside of it and number of breaks taken during the workday at the start and after 12 months.

In 2015, Chapman [16] conducted an RCT to measure the effectiveness of a WHP intervention on physical activity in 254 office workers in Australia. It measured motivation with proprietary items, amount of moderate or vigorous exercise per week and whether or not they already did physical exercise in the past at the start and after 6 months.

In 2015, Steinberg [17] conducted an RCT to determine the impact of a WHP program on nutrition and physical activity in 1395 workers of a company in the US. They measured weight, waist circumference, TG, HDL, BP, blood glucose and costs derived from healthcare with return on investment (ROI) at the start and after 12 months.

Edmunds [18], in 2013, conducted a quasi-experimental study to evaluate the effectiveness of a WHP program on physical activity at 17 SMEs with a sample of 89 workers in the United Kingdom. It measured satisfaction with life using the Satisfaction with Life Scale (SWLS), perceived stress using the Perceived Stress Scale (PSS), mood using the Positive and Negative Affect Scale (PANAS), about $\mathrm{PA}$, number of days they performed moderate-vigorous PA, BMI and general 
health. They also collected qualitative data through focus groups about maintenance of the change in PA and improvements for health and wellbeing as well as social relationships. They measured them at the start and after 6 months.

In 2012, Aittasalo [19] conducted an RCT to evaluate the effect of a WHP intervention on sedentary lifestyle and physical activity to promote walking in 241 office employees in Finland. They measured self-perceived state of health, BMI and walking in various situations: at work, for transportation, outside of work, using the stairs, sedentary lifestyle at work and outside of it, using the IPAQ at the start, after 2 months, 6 months and 12 months.

In 2010, Flaxman [20] conducted an RCT to evaluate the impact of a WHP intervention on stress and mindfulness at 2 companies with 311 workers in the United Kingdom. They measured general psychological stress using the 12 -item General Health Questionnaire (GHQ-12) at the start, at 3 months and at 6 months.

Volpp [21] conducted, in 2009, an RCT to evaluate the effectiveness of a WHP program on smoking cessation directed at 878 workers from a US company that involved giving them monetary incentives if they quit smoking. Ethical considerations aside, to assess smoking cessation the trial measured everyday levels with a biochemical measurement in saliva and urine, in addition to collecting the statement of the workers. It also measured nicotine dependence with the Fagerström test at the start, at 6 months, 12 months and 18 months.

Pillastrini [22] conducted an RCT, in 2009, to determine the effectiveness of a WHP program on musculoskeletal disorders (MSDs) and ergonomics to prevent and manage cervical and low back pain in 71 daycare teachers in Italy. To do this, it measured perceived disability due to low back pain using the Roland Morris Disability Questionnaire and the Oswestry Disability Index; in addition, it measured cervical pain and low back pain using the Visual Analog Scale (VAS) at the start and after 2 months.

In 2008, Kobayashi [23] conducted an RCT to investigate the effects of a WHP intervention to reduce stress in a sample of 1071 workers from Japan. For this, it measured work overload, depression levels and the risk that job stress entails for health at the start and after 12 months.

Mackenzie [24], in 2006, conducted an RCT to evaluate the impact of a WHP intervention on mindfulness and stress reduction in 30 nurses and nursing assistants in Canada. To do this, it measured burnout level using the Maslach Burnout Inventory (MBI), relaxation using the Smith Relaxation Dispositions Inventory, job satisfaction using the Intrinsic Job Satisfaction sub-scale of the Job Satisfaction Scale, satisfaction with life using the Satisfaction with Life Scale (SWLS) and purpose of life using the 13-item version of the Orientation to Life Questionnaire at the start and at 1 month.

Of the 17 articles studied, 13 are RCTs, 3 are quasi-experimental studies and 1 is a systematic review that, in turn, included 23 articles, 14 of which are RCTs.

The distribution of countries where the studies were conducted, if we count the articles found ( 16 articles) and those included in the systematic review (23 articles), is as follows: 23 were conducted in the US, 3 in the United Kingdom, 3 
in Germany, 2 in Japan, 2 in Finland, 1 in Denmark, 1 in Italy, 1 in Canada, 1 in Australia, 1 in the Netherlands and 1 in Belgium. A total of 39,913 workers participated in the 39 studies.

As far as the topics of the WHP interventions that have been studied, the 17 articles include 1 on ergonomics and MSDs, 1 on smoking cessation, 3 on stress management and 12 on physical activity, although many of the latter also include topics on nutrition and wellbeing in general, and even psychological wellbeing. As for the systematic review, all the articles studied WHP interventions on physical activity and sedentary lifestyle.

In terms of the intervention evaluation times, 16 of the 17 articles in the collection included a pre-intervention measurement. A pre-intervention measurement was done in all the articles in the systematic review. Furthermore, the most commonly performed follow-up was that done at 6 months and 12 months post-intervention, followed by the evaluation at 18 months. In 3 articles, follow-up was done at 2 months and in 2 articles this was done 3 months post-intervention. One of the articles measured its results at 2 weeks, another after 1 week, another after 1 month and another after 1 and a half months. With respect to the studies from the systematic review, they all did a follow-up 12 months post-intervention, two, three and four years later, and the review even included one study that did a follow-up eight years post-intervention.

The information collected about the indicators used is presented in Table 4.

\section{Discussion}

Almost all the studies reviewed used a mixed analysis of data. On one hand, quantitative variables were observed, such as number of steps per day or BMI. On the other hand, many of the questionnaires used use open-ended questions and are supplemented with interviews about whether the individuals feel stressed or are sleeping well, among other questions. Another qualitative technique used was focus groups, to address relevant aspects of the workers from the sample.

Furthermore, practically all measured participation, adherence and completion levels of the WHP programs. They measured attendance at workshops or completion of online sessions, when they were available. Although this aspect per

Table 4. More frequently documented indicators of effectiveness.

\begin{tabular}{ll}
\hline \multicolumn{1}{c}{ Work Health Promotion Topic } & \multicolumn{1}{c}{ Documented indicators } \\
\hline Ergonomics and MSDs & $\begin{array}{l}\text { Disability due to pain (Roland Morris Disability } \\
\text { Questionnaire) (Oswestry Disability Index) }\end{array}$ \\
Smoking cessation & Pain (VAS) \\
Stress and Mindfulness & Cessation (daily levels in saliva and urine) \\
$\begin{array}{l}\text { Physical Activity and Sedentary } \\
\text { Lifestyle }\end{array}$ & Nicotine dependence (Fagerström test) \\
& + +Return on Investment (ROI) \\
\hline
\end{tabular}


tains more to the process evaluation, it is a similarity between all the studies analyzed that is important to point out.

The geographic distribution of the studies analyzed places the US as the country most experienced in WHP programs. However, per the INSST and as managed by DEPROSEL, more than 600 Spanish organizations currently adhere to the Luxembourg Declaration [25]. These mean that they are committed to WHP and that they undertake actions and design other new actions to promote WHP at their sites. Not all companies with WHP programs conduct and publish studies on the effectiveness of their interventions. However, that does not mean that WHP programs are not being carried out at non-US companies.

Heath promotion effect measurement needs to implement a scoreboard in order to evaluate the impact in persons and organizations. Our results show the evidence that indicators used for the evaluation of current WHP programs are focused to evaluate more classical biomedical parameters or individual job satisfaction than the effects on the organizations as may be the ROI.

In spite of all the used indicators proved sensitivity for identify changes in both, worker's healthy habits and wellbeing status; it is needed, in order to improve the outcomes of WHP programs, to face the effectiveness measurement with a holistic approach as WHO advises [7].

\subsection{Indicators Used}

As shown in Table 3, most indicators found pertain to WHP programs on physical activity and sedentary lifestyle. Within this group of indicators, the most common were BMI, weight, \% body fat, number of steps (either during workday or outside of it and per day or per week), BP and some biochemical values such as lipid profile or glycated hemoglobin. What was referred to in the review as "waist circumference" was also one of the most common measurements within this topic. However, the articles did not specify how this measurement was taken (whether at the level of the navel, iliac crests, etc.). With regard to BMI or weight, most articles did detail whether these values were collected through the statement of the workers or through objective measurements with scales and/or stadiometers.

The same is true with respect to the level of physical activity, minutes of "moderate-vigorous" physical activity or energy output, which was repeated many times in the articles; it also cannot be assured that the measurements were done the same way in the articles reviewed. Some used pedometers while others used accelerometers and there was no consensus about the most correct determination.

Aparicio-Ugarriza et al. [26] concluded that all devices have limitations for objective measurement of human movement and quantification of energy output. Furthermore, most devices for measuring energy output have been shown to underestimate the information collected in cases of low- and very high-intensity physical activity. 
From all this it can be inferred that not only is the indicator important, but that the method of collection also affects the interpretation of the data. This pessimistic consideration should not be a barrier in evaluating the effectiveness of WHP programs. It simply must be considered when designing a WHP intervention so that measurements are done the same way throughout the process. Limitations must be assumed and reduced as much as possible, especially when comparing data between interventions and/or organizations.

After physical activity and sedentary lifestyle, the second most common topic was stress management and mindfulness. The indicators used were repeated among the studies addressing this topic: purpose of life, mood, depression, etc. The difference was the questionnaires chosen to evaluate them. All were used to measure the indicators for which they were designed. What is important is that the investigators who collect that information and interpret it must be properly trained and familiar with the tool. In any case, it should be noted that the Satisfaction with Life Scale was used in two articles. The other questionnaires were not used in more than one article.

There is also no set list of aspects to evaluate for the indicators selected for each topic of the WHP programs. It is not possible to standardize the programs, nor would it be correct to do so. Just as WHP programs are designed individually to meet the specific needs of a given working population, the indicators to be evaluated must also be individualized.

It should be noted that one of the articles reviewed collected the indicator ROI. Return on investment is a financial ratio that shows the benefit obtained versus the investment made. The authors of the article were unclear as to how the ROI study of their WHP program was performed. However, the article in question was carried out in the US, and its social security and health system is decisive when studying and interpreting ROI. That is, the experience provided by this article on measurement of ROI is difficult to extrapolate to other programs that do not share the US social security and health system.

In this sense, the INSST has developed a tool for calculating the ROI of WHP programs, adapted to the Spanish legislative culture. According to the INSST, both the calculator and the ROI indicator are understood not as a financial management tool, but as a pedagogical tool [27] [28]. Inspired by the model of the UK Department of Work and Pensions, which provides a similar calculator, this tool was designed for the planning of future WHP interventions. It allows a 5 -year cost forecast to be contemplated, although if all the data from previous years is available, it allows a simulation of the past to be created. Without a doubt, this is one more tool for evaluating WHP interventions and, in this case, the effectiveness of WHP programs.

It can be accessed free of charge through the link $<$ https://costespromosalud.insst.es/>. The calculator has explanations about its various sections. However, a free public video is also available at $<\underline{\text { https://vimeo.com/321456590 }}>$ that helps explain how the tool works [27] [28]. 


\subsection{Most Common Topics}

In 2010, the WHO stated that the most common topics of WHP programs that have proven to be effective are: increasing physical activity and avoiding sedentary lifestyle, having proper nutrition, quitting smoking or reducing tobacco consumption, preventing consumption of alcohol and other addictions, controlling weight and obesity, managing stress and promoting mental health, achieving work-life balance, facilitating balance and promoting active aging [7].

In this review, it was found that the topics of WHP programs mostly address physical activity, followed by interventions to promote mental health and stress management and, lastly, smoking cessation and ergonomics and MSDs. Except for the intervention on ergonomics and MSDs, the others are in line with topics that have become common. However, there is a lack of targeted WHP programs, for example, on active aging or prevention of other addictions such as gambling, which are increasing problems in these times.

In any case, it must be noted that the profile of each community within an organization is not necessarily the same for a different organization. Therefore, the WHP needs of one company will not be the same as those of another company. In this sense, it is normal for there to be some variability in the topics of WHP programs between studies.

\subsection{Frequency of Evaluation}

As to when indicators should be measured to evaluate the effectiveness of a WHP program, all the studies reviewed except one agree on measuring the situation before starting the intervention.

It seems logical to know the health status of workers prior to the intervention, to be able to compare it afterwards and connect the changes with the activities of the WHP program implemented. That said, it is true that the review included one quasi-experimental study that only performed a measurement at the end of the intervention, after 2 weeks. For this study, it is important to mention that the non-randomized selection of workers for the sample and the small sample size $(\mathrm{n}=8)$ suggest a possible selection bias. This weakens its internal validity.

With respect to the post-intervention analyses, the most common frequency among the studies analyzed was 6 and 12 months after the intervention. If we note the number of studies that measure their indicators before 6 months and compare them with those that do so after a longer period of time, we find that there are more studies that evaluate the results after 6 months than those that measure them earlier. That is, in practice, the effectiveness of WHP interventions is being evaluated at the earliest at 6 months.

Furthermore, the vast majority of articles reviewed perform more than one post-intervention measurement. This review shows that there are more cases that combine 6-month post-intervention measurements with measurements from 12 months and beyond than there are cases that combine the 6-month measurements with periods shorter than that time. 
We must not forget that in matters related to health promotion and improvement of habits, changes are not observable immediately. In fact, some authors have demonstrated that in some populations health results, stemming from changes in habits to other healthier ones, may not be detected for even 3 to 10 years from the start of health promotion programs [29] [30]. Although performing measurements after 10 years is not viable at an organization, due to possible changes in the sample and/or continuation of the WHP program, it is a consideration to keep in mind when determining the times for evaluation of the effectiveness of interventions. That said, these times must not be too soon or too late.

Without forgetting that not all WHP programs work for all companies, based on the results, it may be recommended that the effectiveness of WHP programs be determined 6 months after their start, regardless of whether the organization deems it necessary to carry out more measurements at other critical times during its intervention.

\section{Conclusions}

This review provides new insight about the state of evaluation of WHP programs internationally during the last twenty years.

By knowing the experience of different organizations in WHP programs and evaluation of their effectiveness, decisions about how to evaluate companies' WHP programs can be made based on evidence.

After discussing the difficulties and the common factors found in the review, the following conclusions can be made:

- The most commonly used indicators in the evaluation of WHP programs were: number of steps, weight, BMI, \% body fat, waist circumference, blood pressure, sedentary time, level of physical activity and time of moderate-vigorous physical activity, daily energy output, life purpose, life satisfaction, mood and stress level. However, all indicators found are included in Table 3, by related topics.

- The most commonly addressed topics in WHP programs, from most common to least common, were: increasing physical activity and avoiding sedentary lifestyle, managing stress and mindfulness, smoking cessation and ergonomics and musculoskeletal disorders.

- The frequency with which WHP programs were evaluated included the time prior to the start of the intervention and, once completed, they were usually not measured until 6 months had passed; after that, the measurement was repeated at 12 months.

As mentioned above, WHP interventions should not be standardized. Programs must be designed based on the needs of the organization's workforce. This applies to the program topic, the evaluation indicators and the times for collection of information. This review shares new information based on the evidence found, to guide the reader on this path. 
It has proven to be a heterogeneous field, which is hard-pressed to reach a global consensus. However, in 2008, the WHO recommended the following: "Additionally, it is important to highlight that the lack of results from randomized control trials should not prevent the development and implementation of WHP programs. Identifying and publishing (through non-traditional means if necessary) case reports and examples of international WHP programs can also build supportive evidence and can help planners better understand how to develop WHP programs that fit different workplace contexts."

\section{Acknowledgements}

Jorge Veiga del Cabo PhD, (in memoriam) Editor of Medicina y Seguridad en el Trabajo review, for its commitment to strengthen the scientific edition in Occupational Medicine.

\section{Conflicts of Interest}

The authors declare no conflicts of interest regarding the publication of this paper.

\section{References}

[1] ENWHP (1997) Luxembourg Declaration on Workplace Health Promotion in the European Union.

https://www.enwhp.org/resources/toolip/doc/2018/05/04/luxembourg_declaration. pdf

[2] ENWHP (2012) Promoting Healthy Work for Workers with Chronic Illness: A Guide to Good Practice.

https://www.enwhp.org/resources/toolip/doc/2018/04/20/enwhp_guide_ph_work_fi nal.pdf

[3] ENWHP (2020) The Implementation of Infrastructures for Promoting Workplace Health. 4th Initiative (2002-2004).

https://www.enwhp.org/?i=portal.en.4th-initiative-building-up-infrastructures

[4] INSST (2003) Nota Técnica de Prevención (NTP) 639: La promoción de la salud en el trabajo: Cuestionario para la evaluación de la calidad.

https://www.insst.es/documents/94886/326775/ntp_639.pdf/97403faf-c00c-4fa3-a98 f-e58a56313004

[5] INSST (2020) Portal de Promoción de la Salud. https://www.insst.es/promocion-de-la-salud

[6] Kahan, B. and Goodstadt, M. (2001) The Interactive Domain Model of Best Practices in Health Promotion: Developing and Implementing a Best Practices Approach to Health Promotion. Health Promotion Practice, 2, 43-67. https://doi.org/10.1177/152483990100200110

[7] WHO (2010) Healthy Work Environments: A Model for Action: For Employers, Workers, Policy Makers, and Professionals.

https://www.who.int/occupational_health/publications/healthy_workplaces_model_ action.pdf

[8] Reutman, S. and Lewis, R. (2019) A Move-A-Thon Event: A Workplace Demonstration of a Proposed Alternative Strategy to Incentivize Workers to Engage in 
Physical Activity. Workplace Health \& Safety, 67, 153-158.

https://doi.org/10.1177/2165079918823211

[9] Das, S.K., Mason, S.T., Vail, T.A., Rogers, G.V., Livingston, K.A., Whelan, J.G., Chin, M.K., Blanchard, C.M., Turgiss, J.L. and Roberts, S.B. (2019) Effectiveness of an Energy Management Training Course on Employee Well-Being: A Randomized Controlled Trial. American Journal of Health Promotion, 33, 118-130. https://doi.org/10.1177/0890117118776875

[10] Sandercock, V. and Andrade, J. (2018) Evaluation of Worksite Wellness Nutrition and Physical Activity Programs and Their Subsequent Impact on Participants' Body Composition. Journal of Obesity, 2018, Article ID: 1035871. https://doi.org/10.1155/2018/1035871

[11] Maylor, B.D., Edwardson, C.L., Zakrzewski-Fruer, J.K., Champion, R.B. and Bailey, D.P. (2018) Efficacy of a Multicomponent Intervention to Reduce Workplace Sitting Time in Office Workers: A Cluster Randomized Controlled Trial. Journal of Occupational and Environmental Medicine, 60, 787-795.

https://doi.org/10.1097/JOM.0000000000001366

[12] Van Hoye, K., Wijtzes, A.I., Lefevre, J., De Baere, S. and Boen, F. (2018) Year-Round Effects of a Four-Week Randomized Controlled Trial Using Different Types of Feedback on Employees' Physical Activity. BMC Public Health, 18, 492. https://doi.org/10.1186/s12889-018-5402-0

[13] Rowland, S.A., Berg, K.E., Kupzyk, K.A., Pullen, C.H., Cohen, M.Z., Schulz, P.S. and Yates, B.C. (2018) Feasibility and Effect of a Peer Modeling Workplace Physical Activity Intervention for Women. Workplace Health \& Safety, 66, 428-436. https://doi.org/10.1177/2165079917753690

[14] Dadaczynski, K., Schieman, S.S. and Backhaus, O. (2017) Promoting Physical Activity in Worksite Settings: Results of a German Pilot Study of the Online Intervention Healingo Fit. BMC Public Health, 17, 696. https://doi.org/10.1186/s12889-017-4697-6

[15] Aittasalo, M., Livson, M., Lusa, S., Romo, A., Vähä-Ypyä, H., Tokola, K., Sievänen, H., Mänttäri, A. and Vasankari, T. (2017) Moving to Business-Changes in Physical Activity and Sedentary Behavior after Multilevel Intervention in Small and Medium-Size Workplaces. BMC Public Health, 17, 319. https://doi.org/10.1186/s12889-017-4229-4

[16] Chapman, J., Campbell, M. and Wilson, C. (2015) Insights for Exercise Adherence from a Minimal Planning Intervention to Increase Physical Activity. Health Education \& Behavior, 42, 730-735. https://doi.org/10.1177/1090198115577374

[17] Steinberg, G., Scott, A., Honcz, J., Spettell, C. and Pradhan, S. (2015) Reducing Metabolic Syndrome Risk Using a Personalized Wellness Program. Journal of Occupational and Environmental Medicine, 57, 1269-1274. https://doi.org/10.1097/JOM.0000000000000582

[18] Edmunds, S., Stephenson, D. and Clow, A. (2013) The Effects of a Physical Activity Intervention on Employees in Small and Medium Enterprises: A Mixed Methods Study. Work, 46, 39-49. https://doi.org/10.3233/WOR-121523

[19] Aittasalo, M., Rinne, M., Pasanen, M., Kukkonen-Harjula, K. and Vasankari, T. (2012) Promoting Walking among Office Employees-Evaluation of a Randomized Controlled Intervention with Pedometers and e-Mail Messages. BMC Public Health, 12, 403. https://doi.org/10.1186/1471-2458-12-403

[20] Flaxman, P.E. and Bond, F.W. (2010) Worksite Stress Management Training: Moderated Effects and Clinical Significance. Journal of Occupational Health Psychology, 
15, 347-358. https://doi.org/10.1037/a0020522

[21] Volpp, K.G., Troxel, A.B., Pauly, M.V., Glick, H.A., Puig, A., Asch, D.A., Galvin, R., Zhu, J., Wan, F., DeGuzman, J., Corbett, E., Weiner, J. and Audrain-McGovern, J. (2009) A Randomized, Controlled Trial of Financial Incentives for Smoking Cessation. The New England Journal of Medicine, 360, 699-709.

https://doi.org/10.1056/NEJMsa0806819

[22] Pillastrini, P., Mugnai, R., Bertozzi, L., Costi, S., Curti, S., Mattioli, S. and Violante, F.S. (2009) Effectiveness of an At-Work Exercise Program in the Prevention and Management of Neck and Low Back Complaints in Nursery School Teachers. Industrial Health, 47, 349-354. https://doi.org/10.2486/indhealth.47.349

[23] Kobayashi, Y., Kaneyoshi, A., Yokota, A. and Kawakami, N. (2008) Effects of a Worker Participatory Program for Improving Work Environments on Job Stressors and Mental Health among Workers: A Controlled Trial. Journal of Occupational Health, 50, 455-470. https://doi.org/10.1539/joh.L7166

[24] Mackenzie, C.S., Poulin, P.A. and Seidman-Carlson, R. (2006) A Brief Mindfulness-Based Stress Reduction Intervention for Nurses and Nurse Aides. Applied Nursing Research, 19, 105-109. https://doi.org/10.1016/j.apnr.2005.08.002

[25] INSST (2020) Listado de empresas, organizaciones, e instituciones adheridas en España a la Declaración de Luxemburgo.

https://www.insst.es/documents/94886/581928/Listado+de+empresas+y+organizaci ones+adheridas+a+la+Declaraci\%C3\%B3n+de+Luxemburgo+2020.pdf/f56c446b-d $\underline{43 e-4 e a c-8 a e c-d 0 b c 45 d 89 d 97 ? t=1611150597501}$

[26] Aparicio-Ugarriza, R., Mielgo-Ayuso, J., Benito, P.J., Pedrero-Chamizo, R., Ara, I. and González-Gross, M. (2015) Physical Activity Assessment in the General Population; Instrumental Methods and New Technologies. Nutricion Hospitalaria, 31, 219-226.

[27] INSST (2020) Herramienta para la valoración de los programas de bienestar laboral. http://costespromosalud.insst.es

[28] PRL Innovación (2020) Webinar: Herramienta del INSST para valorar programas de promoción de la salud. https://vimeo.com/321456590

[29] Pluye, P., Potvin, L. and Denis, J.L. (2004) Making Public Health Programs Last: Conceptualizing Sustainability. Evaluation and Program Planning, 27, 121-133. https://doi.org/10.1016/j.evalprogplan.2004.01.001

[30] Roussos, S.T. and Fawcett, S.B. (2000) A Review of Collaborative Partnerships as a Strategy for Improving Community Health. Annual Review of Public Health, 21, 369-402. https://doi.org/10.1146/annurev.publhealth.21.1.369 